\title{
Effect of implementing epilepsy educational guidelines on nurses' performance and patients' outcomes
}

\author{
Walaa El-khanany Zahran, Wafaa Ismail Sherif, Hanan Abo-Bakr Mohamed \\ Medical-Surgical Nursing Department, Faculty of Nursing, Mansoura University, Egpyt
}

Received: September 6, 2021

DOI: $10.5430 / \mathrm{cns} . v 9 \mathrm{n} 2 \mathrm{p} 20$
Accepted: October 10, $2021 \quad$ Online Published: October 18, 2020

URL: https://doi.org/10.5430/cns.v9n2p20

\begin{abstract}
Objective: Epilepsy is considered one of the most common neurological diseases affecting 65 people worldwide. People with epilepsy are more likely to get injured and die prematurely than the general population. Nurses must acquire professional knowledge related to epilepsy and should strengthen patients to play a more active role in their care to improve their understanding of their diseases. The study aimed to evaluate implementing epilepsy educational guidelines on nurses' performance and patients' outcomes.

Methods: A quasi-experimental research design was conducted at the Neurology department in Mansoura University Hospital. This study sample is a convenient sample of 28 nurses and a purposive sample of 60 adult patients with epilepsy who attend the neurological department in Mansoura University Hospital.

Results: The results indicate a significant improvement in nurses' knowledge and practice regarding epilepsy. Also, it helped to improve patients' knowledge and thus promoted epilepsy self-management behaviors in the study group.

Conclusions: The designed nursing guidelines have achieved their objectives by improving nurses' knowledge and practice regarding epileptic patient care, in addition to improving patients' knowledge and epilepsy self-management scale for the study group compared with the control group.
\end{abstract}

Key Words: Epilepsy educational guidelines, Nurses’ performance, Patients' outcomes

\section{INTRODUCTION}

Epilepsy is one of the most common neurological diseases. Approximately 65 million people worldwide have epilepsy. ${ }^{[1]}$ Epilepsy is a chronic disease caused by the excessive discharge of nerve cells in the brain ${ }^{[2]}$ that causes unprovoked, recurrent seizures. Seizures are abnormal, sudden, and excessive discharges of electrical activity in the brain and are divided into generalized seizures and partial seizures. Generalized seizures affect the whole brain, but partial can only affect part of the brain. ${ }^{[3]}$ Compared with the general population, epilepsy triples the risk of injury and premature death. ${ }^{[4]}$ Ten million people in Africa directly have epilepsy, accounting for approximately $20 \%$ of the global population. ${ }^{[5]}$ The prevalence of idiopathic epilepsy among 6-14-year-old school students in Gharbia Province is 7.2/1,000. ${ }^{[6]}$ The lifetime prevalence of epilepsy among citizens of Al-Manial Island in Egypt is 6.9 per 1,000 residents, and the prevalence of active epilepsy is 5.1 per 1,000 residents. ${ }^{\text {[7] }}$ The lifetime prevalence of epilepsy in Kussel City, Red Sea Province is 5.5/1000. ${ }^{[8]}$ The best care of patients with epilepsy requires a healthcare professional who is prepared and able to manage the patient. ${ }^{[9]}$ In addition to using evidence-based drug treatment, following a healthy lifestyle, and treating other diseases, priority should be given to pa-

*Correspondence: Walaa El-khanany Zahran; Email: w.zahran1 @yahoo.com; Address: Medical-Surgical Nursing Department, Faculty of Nursing, Mansoura University, Egpyt. 
tients and their families to actively participate in treatment to obtain high-quality care. ${ }^{[10]}$ Research has recognized gaps in the understanding of epilepsy among health professionals. ${ }^{[10]}$ At the same time, limited educational interventions have been developed to raise nurses' awareness of epilepsy, ${ }^{[11]}$ so further research is needed to provide nurses with the knowledge and skills needed to improve the quality of patient care.

\subsection{Aim}

The study aimed to evaluate implementing epilepsy educational guidelines on nurses' performance and patients' outcomes

\subsection{Research hypothesis}

H1: Nurses' performance will be improved after educational guidelines implementation.

H2: There will be a difference between patients' outcomes before and after educational guidelines implementation for nurses.

\section{METHODOLOGY}

\subsection{Research design}

A quasi-experimental research design was utilized in this study.

\subsection{Setting}

This study was conducted at the Neurology department in Mansoura University Hospital.

\subsection{Participants}

A convenient sample of 28 nurses (all available nurses were working in the Neurology department). A purposive sample of sixty epileptic adult patients was used. Patients were assigned into two matched groups; control group (A) involved 30 patients who attended the neurological ward before implementing educational guidelines for nurses, and study group (B) involved 30 patients who attended the neurological ward after implementing educational guidelines. Patients who had a mental illness were excluded from the study.

\subsection{Tools}

Four tools were used in the study for data collection. The first and second tools for nurses, the third and fourth tools for patients. Except Tool IV, all tools are verified and reviewed by the researcher on the relevant literature, as shown below

\subsubsection{Tool I: Nurses' Interview Questionnaire}

This tool was developed based on a literature review and consisted of 2 parts:

Part 1: socio-demographic datasheet: Demographic characteristics of nurses consisted of 7 items (age, gender, mari- tal status, educational level, number of experience years as general, years of experience worked as an epileptic nurse, attending any training sessions for epilepsy).

Part 2: Nurses' knowledge about epilepsy consisted of 15 questions divided into two main headings: General knowledge regarding epilepsy questions from 1 to 10 and Nurses' knowledge regarding nursing care of patients with epilepsy questions from 11 to 15 .

Scoring system of nurses' knowledge about epilepsy questionnaire sheet was done as follows:

Each question had a group of answers points, each correct answer was given one degree, while wrong, missed, or unknown answer was given zero. Every question contained one or more correct answers. Then scores were summed up to get the total score for nurses' knowledge about epilepsy. The total knowledge score was computed out of 157 degrees. The total knowledge score was distributed as follows (see Table 1).

Table 1. Total knowledge score

\begin{tabular}{ll}
\hline Scale & $\%$ \\
\hline Good & $\geq 75$ \\
Fair & $50-74$ \\
Poor & $<50$ \\
\hline
\end{tabular}

\subsubsection{Tool II: Nurses' Practice Observational Checklist}

This tool assessed nurses' practice during and after epileptic attacks pre, post, and three-month follow-up implementation of educational guidelines. It was developed based on a literature review and consisted of 20 items with two main sections; during and after the attack.

The Scoring system of nurses' practice observational checklist was done as follows:

The scoring system was calculated as one degree for done and zero for not done, and the total score was 20 degrees (12 degrees for during attack and 8 degrees for after attack). The total nurses' practice score was distributed as follow (see Table 2).

Table 2. Total nurses' practice score

\begin{tabular}{ll}
\hline Scale & $\%$ \\
\hline Satisfactory & $\geq 60$ \\
Unsatisfactory & $<60$ \\
\hline
\end{tabular}

\subsubsection{Tool III: Patients' Interview Questionnaire}

This tool was developed based on a literature review and consisted of four parts: Parts 1, 2, and 3 were used two times 
to collect baseline data for both control and study group. Part 4 was used three times to measure the knowledge regarding epilepsy before, after, and follow up after three months of implementation of educational guidelines. The comparison was made between the two groups.

Part 1: Demographic characteristics of patients and consisted of 5 items (age, gender, marital status, occupation, educational level).

Part 2: Patients' health history used to assess patients' present history, past medical history, family history and consisted of 7 items (diagnosis, seizure type, seizure symptoms, etc....

Part 3: Criteria of epileptic fits included four items (aura criteria, seizure duration, attacks frequency, and period since last seizures).

Part 4: Patients' knowledge about epilepsy consisted of 12 items (definition, causes, aura definition, aura manifestation, complication, treatment, etc....

Scoring system of patients' knowledge about epilepsy questionnaire:

Each question had a group of answers points, each correct answer was given one degree, while wrong, missed, or unknown answer was given zero. Every question contained one or more correct answers. The total knowledge score was computed out of 92 degrees. The total knowledge score was distributed as follows (see Table 3).

Table 3. Total knowledge score

\begin{tabular}{ll}
\hline Scale & $\%$ \\
\hline Good & $\geq 75$ \\
Fair & $50-74$ \\
Poor & $<50$ \\
\hline
\end{tabular}

\subsubsection{Tool IV: Epilepsy Self-Management Scale (ESMS)}

ESMS was developed by DiIorio et al. 2004. ${ }^{[12]}$ It was adopted and translated into Arabic by the researcher, the item "*SM 36. I drink a lot of alcoholic beverages such as beer, wine, and whiskey" was replaced by "cigarette smoking" as this item is uncommon in our country due to religious and cultural restrictions. ESMS has been used for patients pre-implementing educational guidelines (control group) and after implementing educational guidelines (study group). It's a popular, known, well-validated self-reported scale to evaluate the frequency of patients during task performance which helps deal with their seizures. ${ }^{[13]}$

There are 12 negative items for which scores are taken by reverse coding, so the total score ranges from 38 to 190 , with higher scores indicating more frequent use of self- management strategies.

\subsection{Methods}

- Administrative process: A written approval to conduct the study from the Research Ethics Committee of Faculty of Nursing and Mansoura University hospital, the responsible authority to collect data.

- Consent has been obtained from all the participants who accept participating in this study after explaining the aim, benefits, and nature. Participants were informed that their participation was voluntary.

- Tools were tested for validity \& reliability, and then essential modifications were done accordingly. Before starting data collection, a pilot study was done on $10 \%$ of available nurses ( 3 nurses) and $10 \%$ of patients ( 6 patients). They were excluded from the total studied sample.

- A colored Booklet containing the content of educational guidelines was designed by the researcher and tested for content validity by a jury of 7 experts in the field of Medicine and Nursing, and the necessary modification was done. It was written in a simple Arabic language, and photos were added to help the nurses to understand the content. Also, a concise booklet was given to patients who participated in the study at the end of data collection as a gift.

\subsection{Data collection}

Data collection extended over ten months from the first of November 2019 to the end of August 2020, beginning with nurses collecting nurses' demographic characteristics, assess nurses' baseline knowledge and practice about epilepsy before implementation of educational guidelines, followed by collecting data of control group then implementation of educational guidelines for nurses and after that data of study group was collected to compare between two groups and evaluate the effect of implementing epilepsy educational guidelines on nurses' performance and patients' outcomes.

\subsection{Filed work}

The framework of the study was conducted according to three phases as the following: (1) Assessment and planning phase. (2) Implementation phase. (3) Evaluation phase.

\subsubsection{Assessment and planning phase}

(1)Assessment:

- The researcher started by introducing herself to the nurses and giving them a brief idea about the aim of the study.

- All participants were interviewed individually to collect the necessary data using all the study tools in the researcher's presence.

(2) Planning:

- According to the finding of the assessment; goals, priori- 
ties, and expected outcomes was formulated.

- In this phase, four educational sessions for nurses were planned (three theoretical educational sessions and one practical training session) to provide nurses with general knowledge about epilepsy, help them to follow up safety precautions during and after convulsion episodes, and enable them to give patients the required knowledge and skills to stay safe outside hospital.

\subsubsection{Implementation phase}

- Developed epilepsy educational and practical sessions were implemented for all nurses. It was conducted in 4 sessions; each theoretical educational session took (20-30 minutes), and the practical training session took (30-45 minutes) according to the items discussed in each session and the attention span of the nurses.

- Five nurses groups have been established; each group included 5 to 6 nurses; during the interview, the researcher utilized discussion, demonstration, re- demonstration, pictures, videos to attract nurses' attention and motivate them to participate.

- At the beginning of the session, research started by donning revision on the previous session then mentioned objectives of the new session. During each session, the researcher used brief, clear, simple words. At the end of the session, the investigator gives $10 \mathrm{Ms}$ for open discussion and to obtain feedback.

\subsubsection{Evaluation phase}

(1) Immediately post implementing educational guidelines to nurses.

(2) Follow up after three months:

(A) Nurses: The same Interview questionnaire and practice checklist used in pretests were used during the evaluation phase using tool I part 2, tool II.

Table 4. Demographic characteristics of the studied nurses $(\mathrm{N}=28)$

\begin{tabular}{|c|c|c|}
\hline Items & No $(n=28)$ & $\%$ \\
\hline \multicolumn{3}{|l|}{ Gender } \\
\hline Male & 7 & 25 \\
\hline Female & 21 & 75 \\
\hline \multicolumn{3}{|l|}{ Age group } \\
\hline $20-29$ & 15 & 53.6 \\
\hline $30-39$ & 9 & 32.1 \\
\hline $40-49$ & 4 & 14.3 \\
\hline $50-60$ & 0 & 0 \\
\hline Mean $\pm S D$ & $31.142 \pm 8.809$ & \\
\hline \multicolumn{3}{|l|}{ Marital status } \\
\hline Married & 17 & 60.7 \\
\hline Single & 10 & 35.7 \\
\hline Widow & 1 & 3.6 \\
\hline \multicolumn{3}{|l|}{ Educational level } \\
\hline Nursing school & 5 & 17.9 \\
\hline Technical nursing institute & 21 & 75.0 \\
\hline Bachelor of nursing & 2 & 7.1 \\
\hline \multicolumn{3}{|l|}{ Working as a nurse from: } \\
\hline $1-4$ years & 14 & 50.0 \\
\hline $5-10$ years & 4 & 14.3 \\
\hline More 10 years & 10 & 35.7 \\
\hline \multicolumn{3}{|c|}{ Years of experience as an epileptic nurse } \\
\hline less 6 years & 15 & 53.6 \\
\hline $6-9$ years & 2 & 7.1 \\
\hline $10-20$ years & 6 & 21.4 \\
\hline More than 20 years & 5 & 17.9 \\
\hline Mean $\pm S D$ & $10.678 \pm 9.599$ & \\
\hline \multicolumn{3}{|c|}{ Attending epilepsy training courses } \\
\hline Yes & 10 & 35.7 \\
\hline No & 18 & 64.3 \\
\hline
\end{tabular}


(B) Patients (Study group): Patients' Interview Questionnaire (tool III) part 4 was used to assess patients' knowledge about epilepsy to evaluate educational guidelines' effect on patient outcomes.

Epilepsy Self-Management Scale (Tool IV) was used to assess the frequency with which individuals (study group) perform tasks that help manage their seizures after applying educational guidelines to nurses.

\section{Results}

The collected data were analyzed statistically and the results are divided into three sections as following parts:

(1) Section 1: Characteristics of nurses

(2) Section 2: Characteristics of patients

(3) Section 3: Correlation between different variables (Nurses and Patients)

\subsection{Section 1: Characteristics of nurses}

Table 4 shows the demographic characteristics of nurses. In terms of gender, it can be observed that three-quarters (75\%) of nurses are female, with an average age of $31.14 \pm 8.80$ years. As for marital status, three-fifths of the research nurses are married $(60.7 \%)$. The proportion of technical nursing institutions is the largest because three-quarters $(75 \%)$ of the nurses participating in the research graduated from technical nursing institutions (75\%). In comparison, only (7.1\%) of the study nurses graduated with a Bachelor of Nursing.

In terms of nurses' years of experience, half of the study nurses have worked for less than five years, and slightly more than one-third $(35.7 \%)$ of nurses have worked for more than ten years, with an average of $10.678 \pm 9.599$ years of experience as epilepsy nurses. Regarding participating in epilepsy training courses, about two-thirds $(64.3 \%)$ of the sample of nurses studied had not participated in epilepsyrelated training courses.

Figure 1 illustrates the knowledge level of the nurse. It is noticed that less than one-fifth $(17.9 \%)$ of the nurses studied had a good knowledge level in the pretest, which increased to two-fifths $(42.9 \%)$ in the posttest, and then became one third (35.7\%), but still higher than the pretest. This finding is a significant improvement in total nurses' knowledge pre, post, and followed up educational guidelines implementation.

Figure 2 illustrates the total score of nurse practice. It is noticed that three-quarters $(75 \%)$ of the nurses studied had a satisfactory level of practice after implementing the educational guidelines. In comparison, the level of practice before the implementation of the educational guidelines was $7.1 \%$. The implementation guidelines became $71.4 \%$ during follow-up.

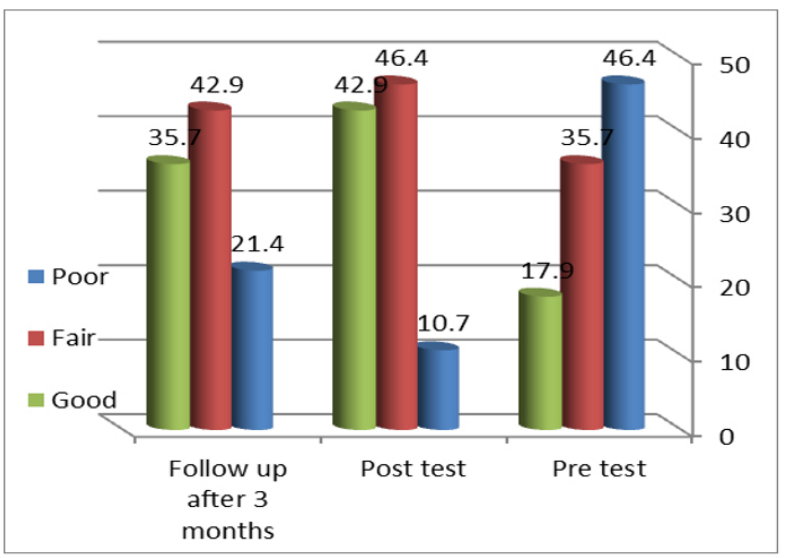

Figure 1. Total nurses' knowledge pre, post, and followed up educational guidelines implementation

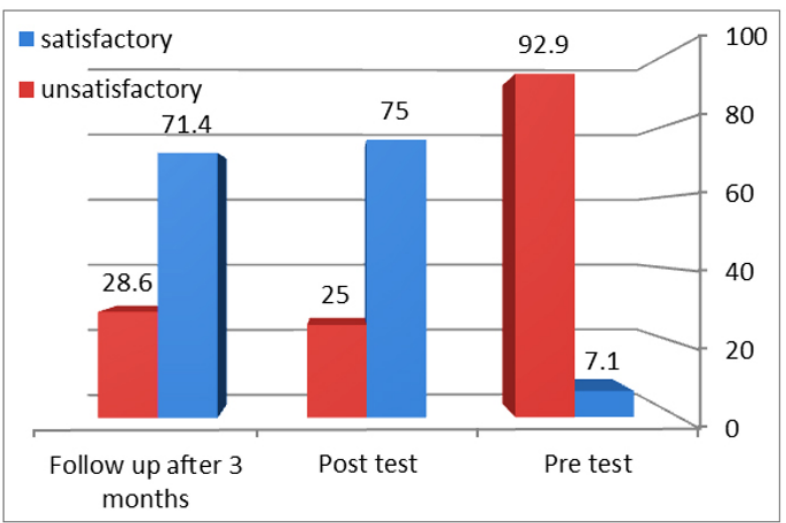

Figure 2. Total nurses' practice levels pre, post, and followed up educational guidelines implementation

\subsection{Section 2: Characteristics of patients}

Table 5 shows the demographic characteristics of the patients. The average age of the control group of patients included in the study was $(39.133 \pm 11.128)$ years, and the average age of the study group was $(39.033 \pm 10.838)$ years. Regarding gender, more than half of the control group $(56.7 \%)$ and about two-thirds $(66.7 \%)$ of the study group were males. In terms of marital status, half of the patients in the control group (50\%) and more than two-fifths (43.3\%) in the study group were married. More than one-third of the patients in the control group and less than half of the patients in the study group (36.7\% and $46.7 \%$ ), respectively, were single.

Regarding education level, the table shows that about half of the study patients graduated from the institute, and the proportions of the control group and the study group were $50 \%$ and $56.7 \%$, respectively. Regarding occupations, it was noted that approximately two-thirds of the study patients were not working at the current time of the study $(60 \%)$ of the study group and (66.6\%) of the control group. There is symmetry between the two studied patients' groups. 
Table 5. Demographic characteristics of studied patients' groups $(N=60)$

\begin{tabular}{|c|c|c|c|c|c|c|}
\hline \multirow{3}{*}{ Items } & \multirow{2}{*}{\multicolumn{2}{|c|}{$\begin{array}{c}\text { Control group } \\
\text { Pretest }\end{array}$}} & \multirow{2}{*}{\multicolumn{2}{|c|}{$\begin{array}{c}\text { Study group } \\
\text { Posttest } \& \text { follow-up }\end{array}$}} & \multirow{2}{*}{\multicolumn{2}{|c|}{ Significance tes }} \\
\hline & & & & & & \\
\hline & No (30) & $\%$ & No (30) & $\%$ & $p$ & $\chi^{2}$ \\
\hline \multicolumn{7}{|l|}{ Age group } \\
\hline $20-29$ & 10 & 33.3 & 9 & 30.0 & \multirow{5}{*}{.937} & \multirow{5}{*}{0.414} \\
\hline $30-39$ & 7 & 23.3 & 9 & 30.0 & & \\
\hline $40-49$ & 5 & 16.7 & 4 & 13.3 & & \\
\hline $50-60$ & 8 & 26.7 & 8 & 26.7 & & \\
\hline Mean $\pm S D$ & \multicolumn{2}{|c|}{$39.133 \pm 11.128$} & \multicolumn{2}{|c|}{$39.033 \pm 10.838$} & & \\
\hline \multicolumn{7}{|l|}{ Gender } \\
\hline Male & 17 & 56.7 & 20 & 66.7 & \multirow{2}{*}{.425} & \multirow{2}{*}{0.635} \\
\hline Female & 13 & 43.3 & 10 & 33.3 & & \\
\hline \multicolumn{7}{|l|}{ Marital status } \\
\hline Married & 15 & 50.0 & 13 & 43.3 & \multirow{4}{*}{.646} & \multirow{4}{*}{0.724} \\
\hline Single & 11 & 36.7 & 14 & 46.7 & & \\
\hline Widow & 4 & 13.3 & 0 & 0 & & \\
\hline Divorced & 0 & 0 & 3 & 10.0 & & \\
\hline \multicolumn{7}{|l|}{ Educational level } \\
\hline Illiterate & 5 & 16.7 & 4 & 13.3 & \multirow{4}{*}{.843} & \multirow{4}{*}{0.827} \\
\hline Read and write & 5 & 16.7 & 6 & 20.0 & & \\
\hline Institute & 15 & 50.0 & 17 & 56.7 & & \\
\hline University & 5 & 16.7 & 3 & 10.0 & & \\
\hline \multicolumn{7}{|l|}{ Occupation } \\
\hline Free work & 3 & 10 & 5 & 16.7 & \multirow{5}{*}{.895} & \multirow{5}{*}{0.605} \\
\hline Housewife & 5 & 16.7 & 5 & 16.7 & & \\
\hline Do not work & 20 & 66.6 & 18 & 60.0 & & \\
\hline employee & 0 & 0 & 0 & 0 & & \\
\hline Others & 2 & 6.7 & 2 & 6.7 & & \\
\hline
\end{tabular}

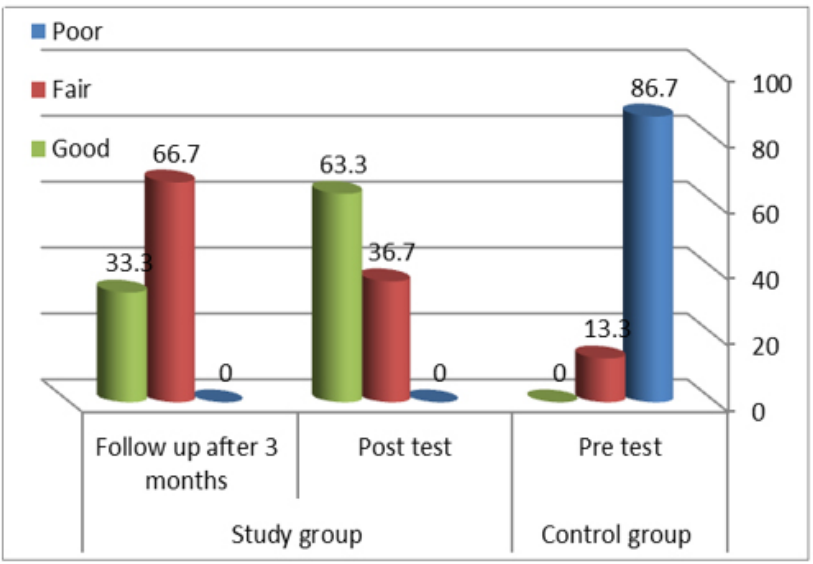

Figure 3. Total patients' knowledge levels pre, post, and follow up after 3 months of educational guidelines implementation

Figure 3 shows the total knowledge level of the patient. It is noticed that most of the control group (86.7\%) had a poor level of knowledge before implementing the educational guidelines. In the posttest, almost two-thirds (63.3\%) of the study group improved to good, becoming one-third (33.3\%) in the follow-up, this was a significant improvement in the Published by Sciedu Press overall patient knowledge before, after, and follow-up after three months of the implementation of the educational guidelines.

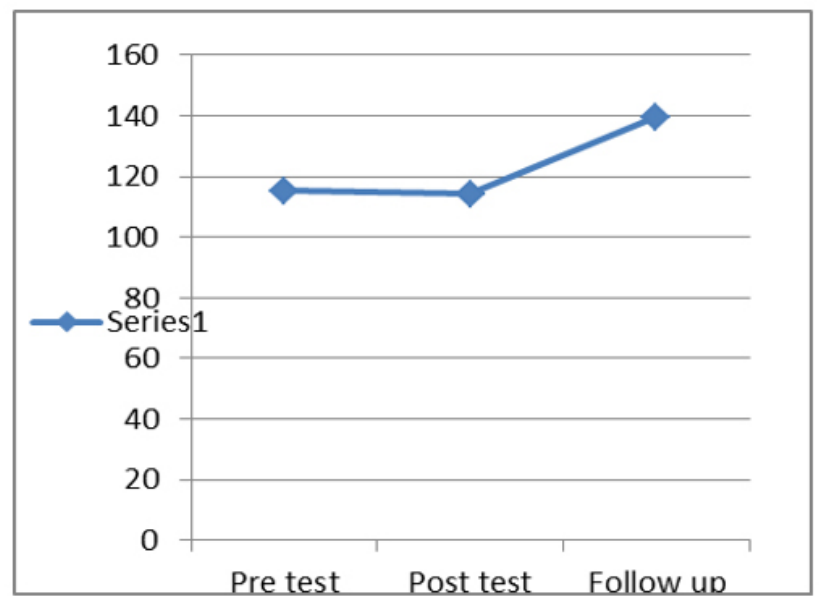

Figure 4. Epilepsy self-management scale (ESMS) pre, post, and follows up after three months of educational guidelines implementation

Figure 4 illustrates the average difference between ESMS 
total scores. It can be seen from this Figure that the patient's ESMS score has improved significantly during follow-up compared to pretest. There was no significant difference between the baseline assessment data of the control group and the study group between the pretest and the posttest.

Figures 5-11 indicate a positive and mild correlation between nurses' knowledge and practice, where $p$ is found $(p=.008)$. Except that nurse knowledge and practice were moderately positively correlated in the post and follow-up, the reported value was $(p=.001$ and $p=.000)$. It can be seen from the basic data that the patient's knowledge and ESMS are moderately positively correlated before the intervention, postintervention, and during follow-up, and the reported value is ( $p=.004, p=.001$, and $p=.000)$. There was a slight positive correlation between nurse knowledge and patient knowledge in the follow-up test, and $\mathrm{P}$ was $(p=.013)$.

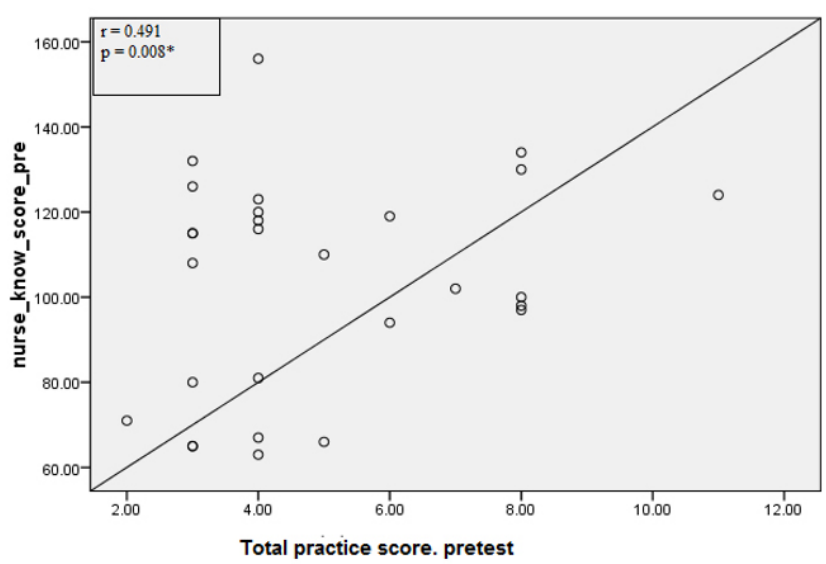

Figure 5. Correlation between nurses' knowledge and practice (pretest)

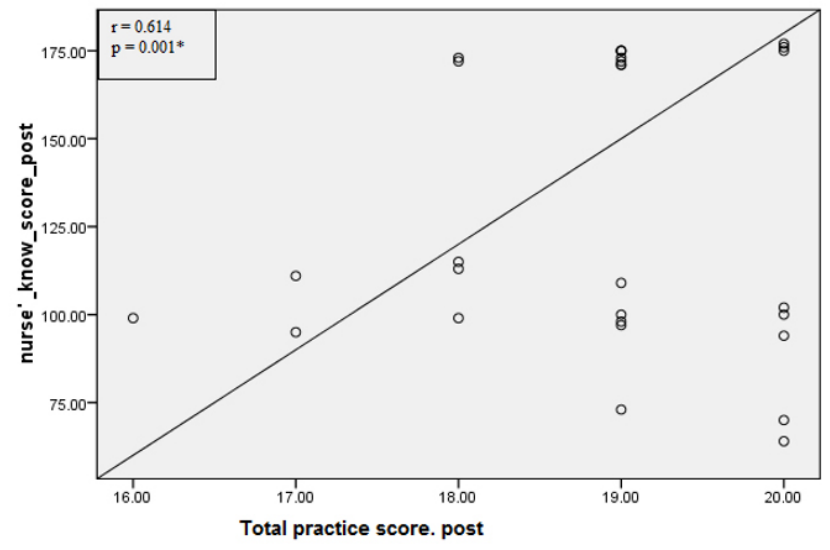

Figure 6. Correlation between nurses' knowledge and practice (posttest)

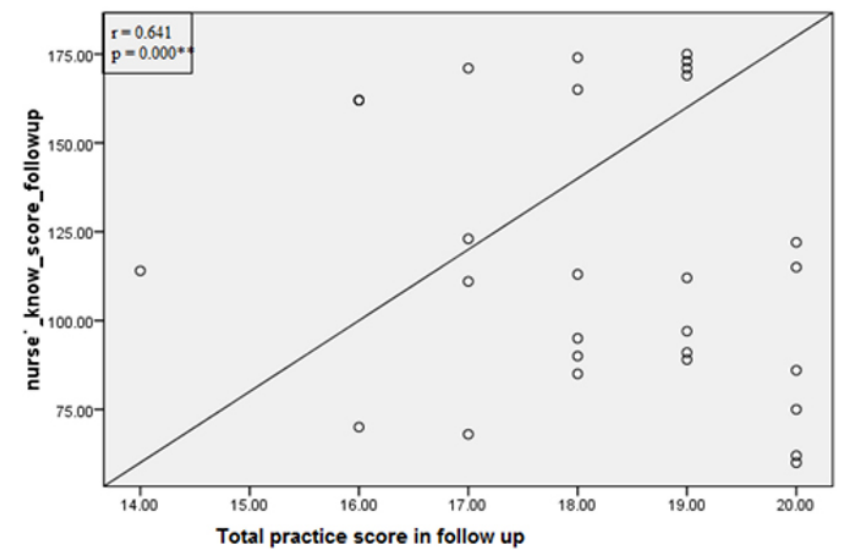

Figure 7. Correlation between nurses' knowledge and practice (follow up after three months)

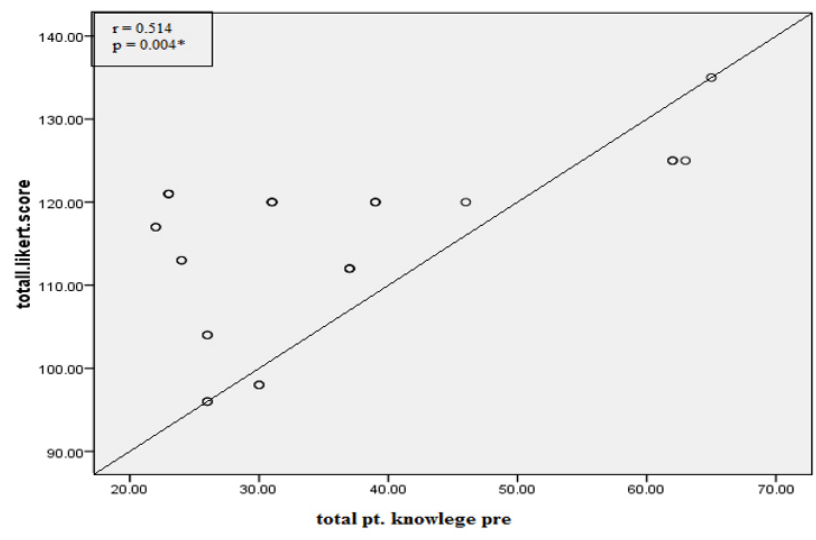

Figure 8. Correlation between patients' knowledge and epilepsy self-management scale (pretest)

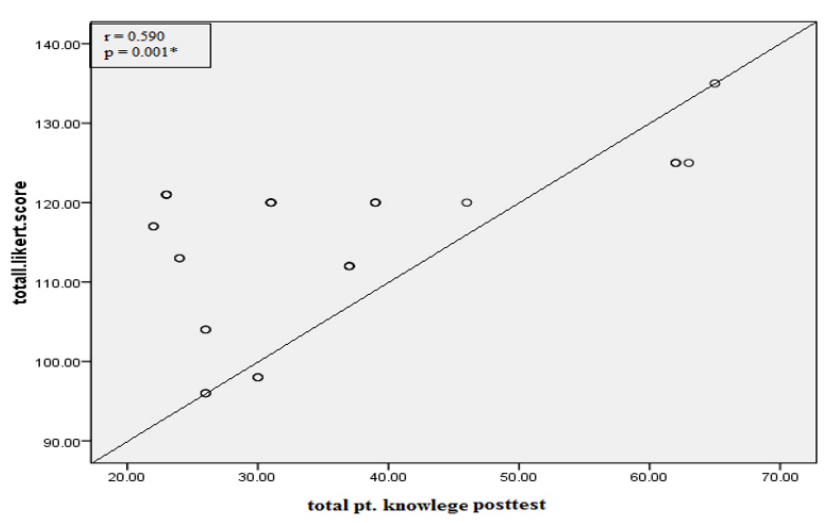

Figure 9. Correlation between patients' knowledge and epilepsy self-management scale (posttest) 


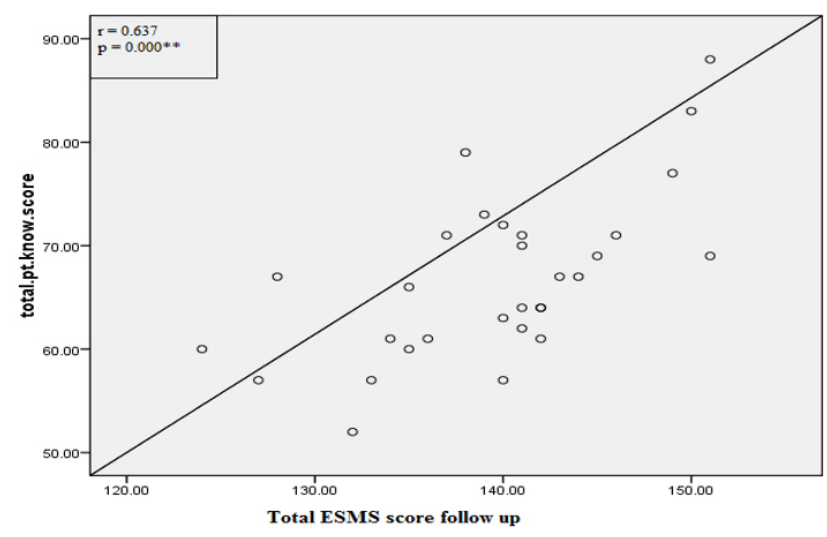

Figure 10. Correlation between patients' knowledge and epilepsy self-management scale (follow up after three months)

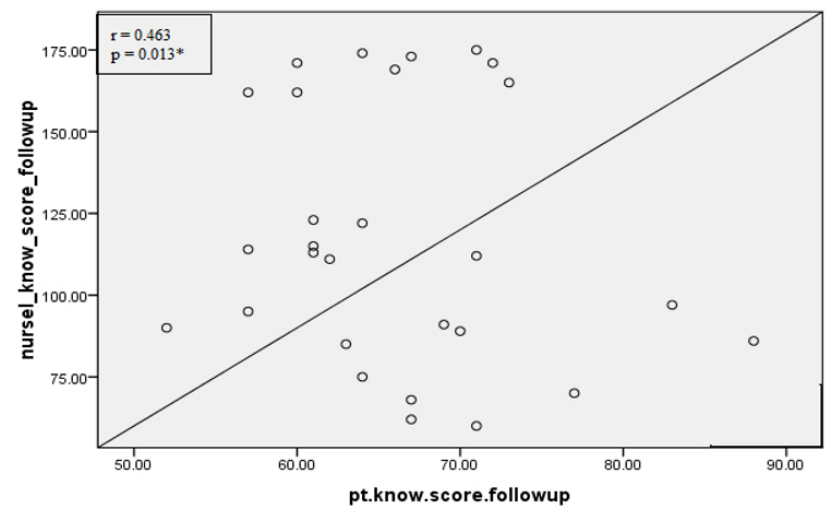

Figure 11. Correlation between nurses' knowledge and patients' knowledge (follow up after three months)

\section{DISCUSSION}

Epilepsy is a chronic disorder that affects the brain and can occur at any age along with life. About 70 million people worldwide have epilepsy, making it one of the most common neurological diseases globally. ${ }^{[14]}$ Self-management behaviors are very important to the management of epilepsy. ${ }^{[15]}$ Nurses, who are the first to recognize seizures in patients with epilepsy in the ward environment, must acquire expertise related to epilepsy ${ }^{[16]}$ and should enhance patients to take a more active role in their care to improve understanding of their illness, increase compliance with treatment regimes, and encourage adoption of healthier lifestyles. ${ }^{[17]}$

The discussion of this study is conducted within three lines: the characteristics of the studied nurses, the characteristics of the studied patients, and the correlation between the study variables.

\subsection{Concerning characteristics of the studied nurses}

The results of this study show that three-quarters of the nurses are women, which is consistent with the report by Higgins et al., $2019^{[18]}$ that most of the research nurses are women. This finding may be because most nurses in our community were females. In terms of age, most nurses are between 20 and 40 years old, with an average age of $31.14 \pm 8.80$ years old; this result is from Dayapoğlu \& Tan, ${ }^{[20]}$ they found that most nurses are between 19 and 45 years old with an average age is $27.10 \pm 5.28$.

In terms of marital status, about three-fifths of nurses are married; this is consistent with the conclusion of El-Masry et al., ${ }^{[20]}$ who summarized most of his samples as married. Regarding the level of education, research shows that threequarters of nurses graduated from technical nursing institutions, but this is inconsistent with Lee et al., ${ }^{[16]}$ which stated that most of the nurses in his study graduated with a bachelor's degree in nursing. This finding may come back to the differences in the setting and location that affect education. Because technical nursing institutions are the most popular in our country, not the Bachelor of Nursing, the cost of education for a few years is relatively low.

Regarding total mean scores of nurses' knowledge about epilepsy; it was shown that there was a significant improvement in the nurses' total knowledge score after implementing educational guidelines; this is consistent with other studies Dayapoglu, ${ }^{[19]}$ Locharernkul et al., ${ }^{[21]}$ Chomba et al., ${ }^{[22]}$ who mentioned that a statistical improvement in the nurses' knowledge score after applying educational sessions.

Regarding the total practice scores of nurses, it was noted that three-quarters of the nurses had satisfactory practice levels after implementing the educational guidelines. These results were supported by El-Masry et al., ${ }^{[20]}$ they reported that all nurses studied in the study have a satisfactory level of practice after implementing the educational guidelines. This finding confirms the importance of education guidelines for improving nurses' care for patients with epilepsy. They also need to keep track and encourage them to maintain the same level of practice and be satisfied with their work.

\subsection{Concerning characteristics of the studied patients}

The presented study showed that the average age of the included patients in the control group was $(39.133 \pm 11.128)$ years, and in the study group was $(39.033 \pm 10.838)$ years. Regarding gender, there are more males than females, which is the same as the results reported by Giuliano et al., ${ }^{[23]}$ it was reported that more than half of his research samples were males, with an average age of $36.9 \pm 16.6$. This finding may be because men are more susceptible to epilepsy than women and are more likely to develop epilepsy in the elderly than young people, reflecting the higher frequency of strokes, neurodegenerative diseases, and tumors in this age group. ${ }^{[24]}$ 
In this study, half of the patients in the control group and more than two-fifths of the patients in the study group are married, graduated from the institute, and currently do not have a job; this is consistent with El-Masry et al., ${ }^{[20]}$ he mentioned most of the patients in his study were married and had secondary education. More than half of the patients were unemployed, which may be related to the employment of epileptic patients is a complex issue due to the diversity of factors that contribute from the clinical condition, family fears, and social acceptance, job types, and related occupational risks.

In terms of patients' awareness of epilepsy, most of the control group had a poor level of knowledge before implementing the educational guidelines. In the posttest, almost twothirds of the study group improved to good, and it became one-third during the follow-up. This finding is consistent with Jothi et al., ${ }^{[25]}$ who reported that about two-thirds of participants have sufficient knowledge, and more than one-third of participants have medium knowledge. No participants have insufficient knowledge about epilepsy education. As with Giuliano et al., ${ }^{[23]}$ they reported that many items have undergone significant changes and that patients' awareness of epilepsy has improved significantly.

Concerning patients' Epilepsy Self-Management Scale (ESMS) score, there was a significant improvement between patients' ESMS score pre and three-month follow-up implementation of educational guidelines and between post and follow-up of the study group. While there was an insignificant difference between baseline assessment of the control group and study group, this finding is in agreement with Bahiraei et al., ${ }^{[26]}$ who reported that the mean score of seizure control, safety, information, lifestyle, and medication in the experimental group before and after the intervention was significantly different. Also consistent with Seethalakshmi et al., ${ }^{[27]}$ who stated that the study group showed an increase in the mean for all components of self-management after three months and a significant increase after six months with no significant difference in the control group. In the same line Hixson ${ }^{[28]}$ reported that there was a statistically significant improvement in total ESMS in a pre (139.7) to post (142.7) comparison.

\subsection{Concerning correlation between study variables (Nurses and Patients)}

These findings prove that there is a significant positive correlation between nurses' knowledge and practice. This finding is consistent with Lee et al. ${ }^{[16]}$ In addition, there is a significant positive correlation between patient knowledge and ESMS before, after, and follow-up implementation of educational guidelines. This result is consistent with Jothi et al. ${ }^{[25]}$ Regarding the correlation between nurse and patient knowledge, the results of this study show a mild positive correlation between them in the follow-up phase, which is consistent with Pfäfflin et al. ${ }^{[29]}$

Finally, it can be concluded that the nursing guide designed for nurses working with epilepsy patients has achieved its goal by improving nurses' knowledge and practice in the care of epilepsy patients, in addition to improving the knowledge of patients in the study group and the ESMS.

\section{Conclusions}

The current study results indicated that implementing epilepsy educational guidelines for nurses showed an improvement in the nurses' knowledge and practice about epilepsy which reflects an improvement in patients' knowledge and epilepsy self-management behaviors.

\section{RECOMMENDATIONS}

Based upon the findings of the present study, the following suggestions can be recommended:

\subsection{For nurses}

- Continuing nursing education and follow-up are important to maintain a high level of nurse knowledge, which is expected to improve the quality of epilepsy care.

- New nurses need to participate in induction training, provide them with basic knowledge and skills, and then evaluate them before taking independent responsibility for patient care.

\subsection{For patients}

- Newly diagnosed patients need group therapy and psychological support therapy courses to adapt to their condition and improve their quality of life.

- Organize patient-centered seminars to allow them to better adapt to the disease.

- People with epilepsy and their caregivers should be encouraged to perform role-playing to prepare for seizures and take safety precautions; this can be helped by providing them with illustrations, colorful, simplified brochures, and pamphlets. - Illustrated booklets should be provided and distributed to every patient with epilepsy admitted to the hospital to remind them of what they can or cannot do to help them cope with the seizure.

\section{ACKNOWLEDGEMENTS}

Special thanks and appreciation goes to my supervisors for their support, valuable instruction and prompt assistance. I would like also to extend my deep thanks nurses, patients who accepted and participated in this study and to all those who directly or indirectly helped me to accomplish this thesis. 


\section{Conflicts of InTERest Disclosure}

The authors declare they have no conflicts of interest.

\section{REFERENCES}

[1] Billakota S, Devinsky O, Kim KW. Why we urgently need improved epilepsy therapies for adult patients. Neuropharmacology. 2019; 107855. PMid: 31751547. https://doi.org/10.1016/j. neuropharm. 2019.107855

[2] Sazgar M, Young MG. Seizures and epilepsy. In Absolute Epilepsy and EEG Rotation Review. Springer, Cham; 2019. 9-46 p. https : //doi.org/10.1007/978-3-030-03511-2_2

[3] Sridhar SP. A Study on Clinical and Biochemical Correlation between Various Types of Seizures and Pseudoseizures. Doctoral dissertation, Stanley Medical College, Chennai. 2019.

[4] Thurman DJ, Logroscino G, Beghi E, et al. Epidemiology Commission of the International League Against Epilepsy. The burden of premature mortality of epilepsy in high-income countries: a systematic review from the Mortality Task Force of the International League Against Epilepsy. Epilepsia. 2017; 58(1): 17-26. PMid: 27888514. https://doi.org/10.1111/epi.13604

[5] Mugumbate J, Zimba AM. Epilepsy in Africa: past, present, and future. Epilepsy \& Behavior. 2018; 79: 239-241. PMid: 29169812. https://doi.org/10.1016/j.yebeh.2017.10.009

[6] Alshahawy AK, Darwish AH, Shalaby SE, et al. Prevalence of idiopathic epilepsy among school children in Gharbia Governorate, Egypt. Brain and Development. 2018; 40(4): 278-286. PMid: 29295801. https://doi.org/10.1016/j.braindev.2017.12.009

[7] Hashem S, Al-Kattan M, Ibrahim SY, et al. Epilepsy prevalence in Al-Manial Island, Egypt. A door-to-door survey. Epilepsy Research. 2015; 117: 133-137. PMid: 26454046. https://doi.org/10.101 6/j.eplepsyres.2015.08.003

[8] El-Tallawy HN, Farghaly WM, Rageh TA, et al. Spectrum of epilepsyprevalence, impact, and treatment gap: an epidemiological study from al-Quseir, Egypt. Neuropsychiatric Disease and Treatment. 2016; 1111. PMid: 27257380. https://doi.org/10.2147/NDT.S877 65

[9] Mahendran M, Speechley KN, Widjaja E. Systematic review of unmet healthcare needs in patients with epilepsy. Epilepsy \& Behavior. 2017; 75: 102-109. PMid: 28843210. https://doi.org/10.101 6/j.yebeh.2017.02.034

[10] Ozuna J, Kelly P, Towne A, et al. Self-Management in Epilepsy Care: Untapped Opportunities. Federal Practitioner. 2018; 35(Suppl 3): S10.

[11] Pitkänen A, Buckmaster P, Galanopoulou AS, et al. Models of seizures and epilepsy. Academic Press; 2017.

[12] Dilorio C, Shafer P, Letz R, et al. Project EASE: A study to test a psychosocial model of epilepsy medication management. Epilepsy \& Behavior. 2004; 5(6): 926-936. PMid: 15624235. https://doi.org/10.1016/j.yebeh.2004.08.011

[13] Bautista RED. Understanding the self-management skills of persons with epilepsy. Epilepsy \& Behavior. 2017; 69: 7-11. PMid: 28219044. https://doi.org/10.1016/j.yebeh.2016.11.022

[14] Trinka E, Kwan P, Lee B, et al. Epilepsy in Asia: disease burden, management barriers, and challenges. Epilepsia. 2019; 60: 7-21. PMid: 29953579. https://doi.org/10.1111/epi.14458

[15] Luedke MW, Blalock DV, Goldstein KM, et al. Self-Management of epilepsy: a systematic review. Annals of Internal Medicine. 2019; 171(2): 117-126. PMid: 31261386. https://doi.org/10.7326/ M19-0458

Published by Sciedu Press
[16] Lee JH, Ju HO, Lee YJ. Effects of an Algorithm-based Education Program on Nursing Care for Children with Epilepsy by Hospital Nurses. Child Health Nursing Research. 2019; 25(3): 324-332. https://doi.org/10.4094/chnr.2019.25.3.324

[17] Fitzsimons M, Normand C, Varley J, et al. Evidence-based models of care for people with epilepsy. Epilepsy \& Behavior. 2012; 23(1): 1-6. PMid: 22134097. https ://doi.org/10.1016/j. yebeh. 20 11.10 .019

[18] Higgins A, Downes C, Varley J, et al. Supporting and empowering people with epilepsy: contribution of the Epilepsy Specialist Nurses (SENsE study). Seizure. 2019; 71: 42-49. PMid: 31203026 https://doi.org/10.1016/j. seizure.2019.06.008

[19] Dayapoğlu N, Tan M. Clinical nurses' knowledge and attitudes toward patients with epilepsy. Epilepsy \& Behavior. 2016; 61: 206209. PMid: 27372960 . https ://doi .org/10.1016/j . yebeh. 20 16.05.009

[20] El-Masry MA, Mohammad ZA, Shehata GA, et al. Effect of Implementing a Designed Nursing Protocol on Nurses' Knowledge and Practice Regarding Epileptic Patients Outcomes. Assiut Scientific Nursing Journal. 2013; 1(1): 139-146. ://doi .org/10.21608/a snj.2013.57393

[21] Locharernkul C, Suwaroporn S, Krongthong W, et al. A study of knowledge and attitude improvement on epilepsy among Thai physicians and nurses. J Med Assoc Thai. 2010; 93(8): 875-84.

[22] Chomba EN, Haworth A, Atadzhanov M, et al. Zambian health care workers' knowledge, attitudes, beliefs, and practices regarding epilepsy. Epilepsy \& Behavior. 2007; 10(1): 111-119. PMid: 17055341. https://doi.org/10.1016/j. yebeh.2006.08.01 2

[23] Giuliano L, Cicero CE, Padilla S, et al. Knowledge, stigma, and quality of life in epilepsy: results before and after a community-based epilepsy awareness program in rural Bolivia. Epilepsy \& Behavior. 2019; 92: 90-97. PMid: 30634158. https://doi.org/10.1016/ j.yebeh.2018.11.036

[24] Beghi E. The epidemiology of epilepsy. Neuroepidemiology. 2020; 54(2): 185-191. PMid: 31852003. https://doi.org/10.1159/ 000503831

[25] Jothi A, Ramamoorthy L, Nair PP. The Effect of Comprehensive Video-Assisted Epilepsy Education on Drug Adherence and SelfCare in People with Epilepsy. Journal of Neurosciences in Rural Practice. 2020; 11(4): 538-544. PMid: 33144788. https://doi.or $\mathrm{g} / 10.1055 / \mathrm{s}-0040-1713841$

[26] Bahiraei N, Dehghani M, Khachian A. The Effect of Educational Program on Self-Management of Patients with Epilepsy: A Randomized Clinical Trial Study. Avicenna Journal of Nursing and Midwifery Care. 2019; 27(5): 361-369. https://doi.org/10.30699/ajn mc. 27.5 .361

[27] Seethalakshmi A, Shankar V, Samson R. Effectiveness of an epilepsy education programme on the self-management among patients with epilepsy. IOSR Journal of Nursing and Health Science. 2015; 4(5): 33-54.

[28] Hixson J. Use of a Digital Self-Management Platform for Improving Access in Epilepsy Patients. 2016; P2.002.

[29] Pfäfflin M, Schmitz B, May TW. Efficacy of the epilepsy nurse: results of a randomized controlled study. Epilepsia. 2016; 57(7): 11901198. PMid: 27265887. https://doi.org/10.1111/epi.13424 